\title{
Kynurenine and Tetrahydrobiopterin Pathways Crosstalk in Pain Hypersensitivity
}

\author{
Ananda Staats Pires ${ }^{1,2}$, Vanessa X. Tan ${ }^{1}$, Benjamin Heng ${ }^{1}$, Gilles J. Guillemin ${ }^{1 *}$ and \\ Alexandra Latini ${ }^{2 *}$ \\ ${ }^{1}$ Neuroinflammation Group, Department of Biomedical Sciences, Centre for Motor Neuron Disease Research, Faculty of \\ Medicine, Health and Human Sciences, Macquarie University, Sydney, NSW, Australia, ${ }^{2}$ Laboratório de Bioenergética e \\ Estresse Oxidativo, Departamento de Bioquímica, Centro de Ciências Biológicas, Universidade Federal de Santa Catarina, \\ Florianópolis, Brazil
}

\section{OPEN ACCESS}

Edited by:

Marianthi Papakosta, Takeda Pharmaceutical Company

Limited, United States

Reviewed by:

Wladyslaw-Lason,

Institute of Pharmacology (PAS),

Poland

Ewa Krystyna

Szczepanska-Sadowska,

Medical University of Warsaw, Poland

${ }^{*}$ Correspondence:

Gilles J. Guillemin

gilles.guillemin@mq.edu.au

Alexandra Latini

a.latini@ufsc.br

Specialty section:

This article was submitted to

Neuropharmacology,

a section of the journal

Frontiers in Neuroscience

Received: 09 December 2019

Accepted: 19 May 2020

Published: 24 June 2020

Citation:

Staats Pires A, Tan VX, Heng B,

Guillemin GJ and Latini A (2020)

Kynurenine and Tetrahydrobiopterin

Pathways Crosstalk in Pain

Hypersensitivity.

Front. Neurosci. 14:620

doi: 10.3389/fnins.2020.00620
Despite the identification of molecular mechanisms associated with pain persistence, no significant therapeutic improvements have been made. Advances in the understanding of the molecular mechanisms that induce pain hypersensitivity will allow the development of novel, effective, and safe therapies for chronic pain. Various proinflammatory cytokines are known to be increased during chronic pain, leading to sustained inflammation in the peripheral and central nervous systems. The pro-inflammatory environment activates additional metabolic routes, including the kynurenine (KYN) and tetrahydrobiopterin (BH4) pathways, which generate bioactive soluble metabolites with the potential to modulate neuropathic and inflammatory pain sensitivity. Inflammation-induced upregulation of indoleamine 2,3-dioxygenase 1 (IDO1) and guanosine triphosphate cyclohydrolase I (GTPCH), both rate-limiting enzymes of $\mathrm{KYN}$ and $\mathrm{BH} 4$ biosynthesis, respectively, have been identified in experimental chronic pain models as well in biological samples from patients affected by chronic pain. Inflammatory inducible $\mathrm{KYN}$ and $\mathrm{BH} 4$ pathways upregulation is characterized by increase in pronociceptive compounds, such as quinolinic acid (QUIN) and $\mathrm{BH} 4$, in addition to inflammatory mediators such as interferon gamma (IFN- $\gamma$ ) and tumor necrosis factor alpha (TNF- $\alpha$ ). As expected, the pharmacologic and genetic experimental manipulation of both pathways confers analgesia. Many metabolic intermediates of these two pathways such as $\mathrm{BH} 4$, are known to sustain pain, while others, like xanthurenic acid (XA; a KYN pathway metabolite) have been recently shown to be an inhibitor of $\mathrm{BH} 4$ synthesis, opening a new avenue to treat chronic pain. This review will focus on the KYN/BH4 crosstalk in chronic pain and the potential modulation of these metabolic pathways that could induce analgesia without dependence or abuse liability.

Keywords: chronic pain, neuropathic pain, inflammatory pain, neuroinflammation, kynurenine, tetrahydrobiopterin, xanthurenic acid, central sensitization 


\section{INTRODUCTION}

The immune and pain-signaling systems are evolutionarily designed to protect the organism by acutely responding to danger (Woolf and Ma, 2007; Woolf, 2010; O'neill et al., 2016). Typically, stimuli that activate both systems elicit inflammation and pain that are adaptive response to overcome the threat, increasing the life-time reproductive success (Beringer and Miossec, 2019). However, many injuries and diseases may perpetuate maladaptive inflammatory reactions, in which pro-inflammatory mediators persistently activate and sensitize neurons at different levels of the nociceptive pathway (Woolf and Costigan, 1999; Costigan et al., 2009a, 2010; Oikawa et al., 2019). These long-lasting sensory changes known as chronic pain, represents a major unmet clinical need (for a review see Woolf and Salter, 2000). This is a significant problem due to the high incidence worldwide (Rice et al., 2016) and lack of effective, specific and safe therapies (Varrassi et al., 2010; Dart et al., 2015; Jones, 2017).

Neuroinflammation is characterized by the infiltration of peripheral immune cells, activation of glial cells and production of inflammatory mediators in the peripheral and central nervous systems (PNS; CNS). This contributes to generate a peripheral and central sensitization that causes long-term pain (Kawasaki et al., 2008; Gao and Ji, 2010). Therefore, targeting these neuroinflammatory processes and molecules may result in an effective analgesic treatment for chronic pain.

\section{CHRONIC PAIN}

Chronic pain is a dysfunctional process defined by longstanding pain sensations of more than three months (IASP, 2019; Treede et al., 2019). Chronic pain is a major health problem worldwide that negatively impacts on the quality of life of the affected individuals, and represents a huge health public costs in both developed and emerging countries (Goren et al., 2014).

Abbreviations: 1-MT, 1-methyl-tryptophan, an IDO1 inhibitor; 3-HAA, 3hydroxyanthranilic acid; 3-HK, 3-hydroxykynurenine; AA, anthranilic acid; AKR, aldoketo reductase; $\mathrm{BH} 4$, tetrahydrobiopterin; CAIA, collagen antibody-induced arthritis; CCI, chronic constriction injury; CFA, complete Freund's adjuvant; CNS, central nervous system; CR, carbonyl reductase; CTLA4, cytotoxic T lymphocyte antigen-4; DHFR, dihydrofolate reductase; DRG, dorsal root ganglia; FDA, Food and Drug Administration; GCH1, gene that codes for the human guanosine triphosphate cyclohydrolase I enzyme; Gchl, gene that codes for the murine guanosine triphosphate cyclohydrolase I; Glu, glutamate, GTP, guanosine triphosphate; GTPCH, guanosine triphosphate cyclohydrolase I; HIV, human immunodeficiency virus; IASP, International Association for the Study of Pain; $\mathrm{IC}_{50}$, concentration at half-maximal inhibition; IDO1, indoleamine 2,3-dioxygenase 1; IFN- $\gamma$, interferon gamma; IL-1 $\beta$, interleukin-1beta; IL-6, interleukin-6; JM6, a KMO inhibitor; KATs, kynurenine aminotransferases; KMO, kynurenine 3-monooxygenase; KYN, kynurenine; KYNA, kynurenic acid; KYNU, kynureninase; LPS, lipopolysaccharides; $\mathrm{NAD}^{+}$, nicotinamide adenine dinucleotide; NMDA, N-methyl-d-aspartate; NMDAR, N-methyl-d-aspartate receptor; NSAIDs, non-steroidal anti-inflammatory drugs; PCD, pterin 4acarbinolamine dehydratase; PNS, peripheral nervous system; PTPS, 6-pyruvoyl tetrahydropterin synthase; Q-1195, a SPR inhibitor; QM385, a SPR inhibitor; QUIN, quinolinic acid; Ro61-6048, a KMO inhibitor; SNI, spared nerve injury; SPR, sepiapterin reductase; Spr, gene that codes for the murine sepiapterin reductase; SPRi, sepiapterin reductase inhibitors; SPRi3, a SPR inhibitor; SSZ, sulfasalazine; TDO, tryptophan 2,3-dioxygenase; TNF- $\alpha$, tumor necrosis factor alpha; Trp, tryptophan; XA, xanthurenic acid.
Approximately $20 \%$ of the adult population in the United States (Dahlhamer et al., 2018), Canada (Shupler et al., 2019), and Europe (Breivik et al., 2006) are affected by chronic pain. Similar prevalence is observed in Australia, about 15\% (Miller et al., 2017), and higher in countries like Brazil and Japan, with a prevalence of around 40\% (Inoue et al., 2015; De Souza et al., 2017). Chronic pain is a major health burden to the society, with annual costs over $\$ 635$ billion per year in the United States alone (Gereau et al., 2014). This exceeds the combined costs of common chronic conditions including, cancer, heart disease, and diabetes (Gereau et al., 2014). The global high incidence of chronic pain is aggravated by the lack of effective and safe treatments; in particular, the development of side effects such as addiction and the risk overdose leading to death (NIDA, 2020).

There are numerous classes of drugs used to treat pain, including serotonin reuptake inhibitors, non-steroidal antiinflammatory drugs (NSAIDs), and opioids (Nalamachu, 2013). Each of these drugs are associated with different adverse events impacting the gastrointestinal, cardiovascular, and renal systems, and their efficacy against chronic pain is controversial (Macario and Lipman, 2001; Brueggemann et al., 2010; Skljarevski et al., 2012; Chou et al., 2014). A recent meta-analysis showed that opioids, the most efficient class of drug against acute pain, provided only minor improvements for people dealing with chronic pain caused by conditions other than cancer (Busse et al., 2018). Moreover, the repeated use of opioids is strongly associated with addiction and risk of death (NIDA, 2020). Therefore, more research is urgently needed to develop pain medications with higher efficacy and safety.

The exact mechanism driving pain persistence is poorly understood. Chronic pain conditions are likely to have distinctive underlying mechanisms that ultimately alter the long-term nociceptive signaling in patients. Indeed, a key and common feature for all chronic pain conditions is a longterm neuronal plasticity in pain-signaling circuits that result in increased neuronal responsiveness to their normal input and/or recruitment of a response to subthreshold inputs (for a review see Woolf and Salter, 2000). The pain-induced neuronal plasticity involves the sensitization of sensory neurons in different anatomical locations along of the PNS and CNS (Woolf, 1983; Latremoliere and Woolf, 2009).

\section{NOCICEPTIVE SIGNALING PATHWAY AND PAIN HYPERSENSITIVITY}

The peripheral primary sensory neurons from the pain-signaling pathway are activated by different noxious stimuli, including thermal, mechanical, or chemical stimuli that have potential or are currently damaging tissue. These specialized primary sensory cells are pseudo-unipolar neurons with the soma anatomically located in the dorsal root ganglia (DRG) and in the trigeminal ganglia (Kandel, 2013). The peripheral terminals of nociceptors are equipped with a range of receptors that transduce noxious stimuli into action potentials, which are then transmitted through the nervous systems. All primary sensory nociceptors, through 
their central terminals, make synaptic connections with secondorder neurons in the spinal cord (for a review see Woolf and Ma, 2007). Some subsets of spinal dorsal horn neurons project axons and transmit pain messages to higher brain centers, including the reticular formation, thalamus, amygdala, and finally the cerebral cortex. These brain regions are associated with autonomic, hormonal, emotional and cognitive aspects of pain, including the perception and consciousness of pain (Mobbs et al., 2009). The neural activity along the pain transmission pathway is inhibited or amplified by ascending and descending neural circuits (for a revision see Woolf, 2018). This modulation allows a wide range of factors to modulate pain sensation and perception, including psychosocial and environmental factors (for a review see Chayadi and Mcconnell, 2019).

\section{NEUROINFLAMMATION IN CHRONIC PAIN}

Growing evidence suggests that persistent inflammation within the PNS and CNS is a factor that drives self-perpetuation and pathologic plasticity changes in sensory neurons, sustaining the chronicity of pain (Kawasaki et al., 2008; Gao and Ji, 2010). Injuries and diseases that directly or indirectly affect the PNS and CNS can elicit neuroinflammatory responses that include activation of resident immune cells, changes in capillary permeability and infiltration of peripheral blood cells (for a review see Zhuang et al., 2005). It has been demonstrated that during inflammation peripheral leukocytes (including neutrophils, monocytes/macrophages and T cells) are able to infiltrate the PNS and CNS, leading to overproduction of a variety of pro-inflammatory cytokines, chemokines, and other pain-related mediators (Costigan et al., 2009b; Kigerl et al., 2009). The neuroinflammatory response is further amplified by the activation of resident glial cells, including microglia and astrocytes. Once activated, these cells undergo hypertrophic changes and increase the release of glial mediators, including numerous trophic factors, chemokines and proinflammatory cytokines that can modulate pain sensitivity (Rojewska et al., 2014b; Figure 1).

While acute neuroinflammation can produce transient peripheral and central sensitization, permanent or repeated neuroinflammation is associated with a long-lasting and even permanent sensitization (Christianson et al., 2011). The literature supports the association between neuroinflammation and various chronic pain conditions, such as neuropathic pain triggered by diabetes, nerve and spinal cord injury, inflammatory pain caused by arthritis, inflammatory bowel disease, cancer related pain, complex regional pain syndrome, and pain caused by drug therapy (Sweitzer et al., 2002; Chua et al., 2019). As an example, a study on post mortem spinal cord samples from human immunodeficiency virus (HIV)-infected patients with neuropathic pain showed increased glial activation and increased inflammatory cytokine levels (Shi et al., 2012).

The exact mechanisms by which neuroinflammation favors the transition from acute pain to persistent pain is still poorly defined. This lack of understanding of the basic mechanisms of pain perpetuation is reflected in the limited efficacy of anti-inflammatory drugs, in addition to the significant side effects (Enthoven et al., 2016). Therefore, new avenues need to be explored in order to manage this unmet clinical condition. In this paradigm, emerging mediators related to inflammationenhanced metabolic pathways, i.e., tetrahydrobiopterin (BH4) and quinolinic acid (QUIN; a KYN pathway metabolite) have been proposed to favor pain hypersensitivity (Latremoliere et al., 2015; Laumet et al., 2017). The innate immune system once activated elicits the synthesis of pro-inflammatory mediators in order to coordinate the inflammatory response. Many of these mediators can transcriptionally upregulate the expression of inducible enzymes, activating the pathological production of BH4 and QUIN (for a review see Guillemin, 2012; Ghisoni et al., 2015a; Figure 1).

\section{THE BIOSYNTHESIS OF BH4}

BH4 is traditionally known as an essential cofactor for the catalytic activity of phenylalanine hydroxylase, tyrosine3-hydroxylase, tryptophan-5-hydroxylase, alkylglycerol monooxygenase, and all nitric oxide synthase isoforms (Thöny et al., 2000). As a consequence, BH4 is crucial for hydroxylation of the aromatic amino acids, resulting in the catabolism of phenylalanine and the synthesis of the catecholaminergic neurotransmitters dopamine and serotonin. $\mathrm{BH} 4$ is also mandatory for the cleavage of ether lipids as well as the biosynthesis of nitric oxide (Thöny et al., 2000; Werner et al., 2011). Recently, our group has uncovered other fundamental physiological roles for basal $\mathrm{BH} 4$ levels, as having antioxidant and anti-inflammatory properties, and being a mitochondrial activator as well as a memory enhancer (Ghisoni et al., 2015a,b, 2016; De Paula Martins et al., 2018; Latini et al., 2018). We also described that exacerbated production of $\mathrm{BH} 4$ is pathogenic, causing pain, increasing the aggressiveness of the immune system and the progression of the symptoms of chronic diseases, including, chronic pain, asthma, multiple sclerosis, ulcerative colitis, rheumatoid arthritis, and cognitive impairment (Latremoliere et al., 2015; Cronin et al., 2018; Fujita et al., 2019).

Physiological basal levels of $\mathrm{BH} 4$ are at tightly controlled concentrations, requiring therefore, a tuned regulation of BH4 synthesis. Three metabolic pathways, namely de novo synthesis, recycling, and salvage pathways cooperate to maintain appropriate intracellular levels of $\mathrm{BH} 4$ (Figure 2). The de novo pathway generates $\mathrm{BH} 4$ from guanosine triphosphate (GTP) through a three-step enzymatic cascade starting with the rate-limiting enzyme guanosine triphosphate cyclohydrolase I (GTPCH), followed by 6-pyruvoyl tetrahydropterin synthase (PTPS) and sepiapterin reductase (SPR) (for a review see Ghisoni et al., 2015a). Alternative to de novo synthesis, intracellular $\mathrm{BH} 4$ levels can be produced via the salvage pathway using sepiapterin and 7,8-dihydrobiopterin as intermediates. Although this pathway is not fully understood, SPR and dihydrofolate reductase (DHFR) appear to be essential enzymes to maintain $\mathrm{BH} 4$ levels without consuming high-energy phosphate containing compounds (Werner et al., 2011). In addition, the catalytic activity of SPR can also be performed by non-specific enzymes, the aldoketo and carbonyl reductases 


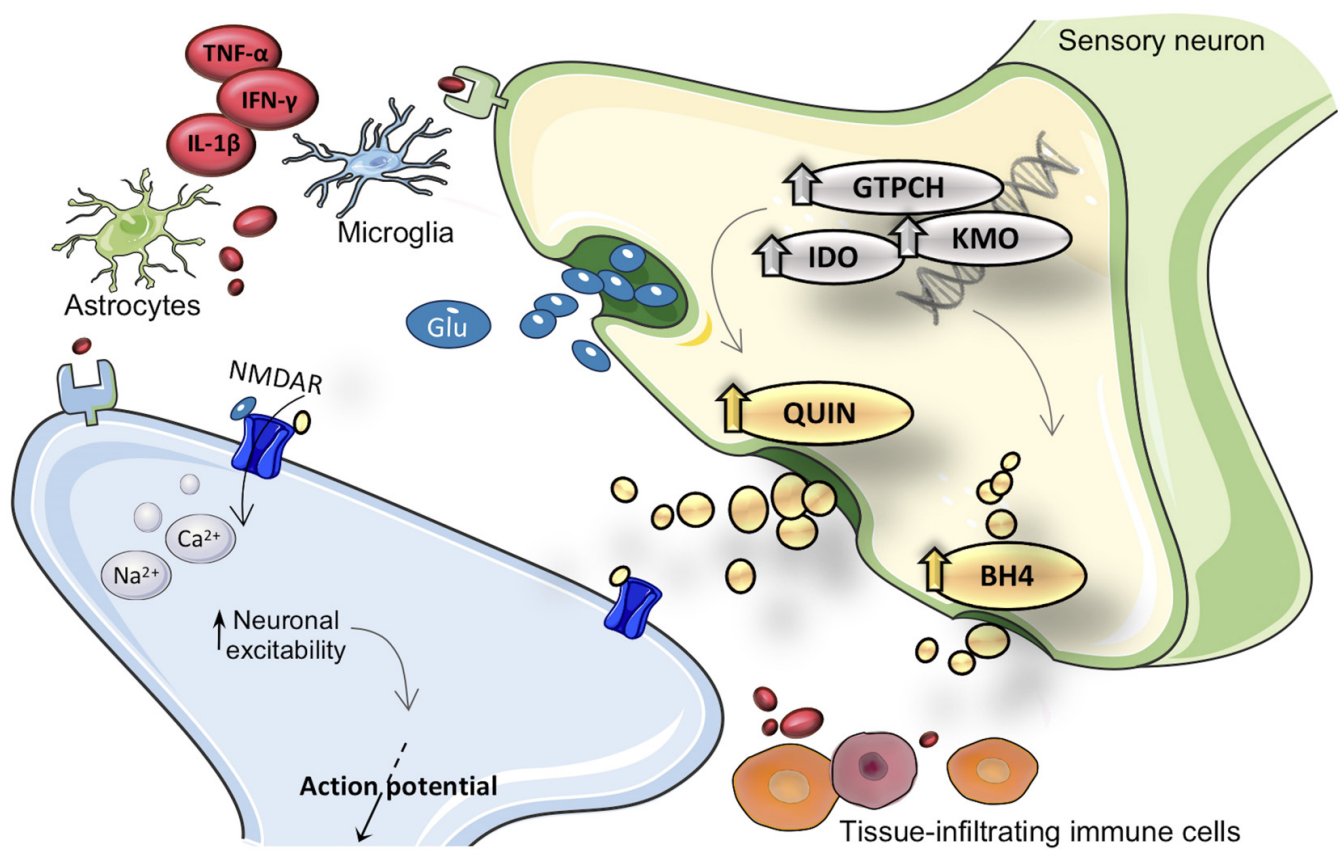

FIGURE 1 | Merger of kynurenine (KYN) and tetrahydrobiopterin (BH4) pathways into inflammation cascade involved in pain hypersensitivity. After inflammatory activation, expression and activity from GTPCH (guanosine triphosphate cyclohydrolase I), IDO1 (indoleamine 2,3-dioxygenase), and KMO (kynurenine 3-monooxygenase) enzymes are enhanced in brain and immune cells. Inflammatory inducible KYN/BH4 pathways upregulation is characterized by increased nociceptive compounds, such as QUIN (quinolinic acid) and $\mathrm{BH} 4$. As a consequence, neurons undergo profound changes in activity, which eventually result in exacerbated pain sensations. The neuroactive compound QUIN is NMDAR ( $\mathrm{N}$-methyl-d-aspartate receptor) agonist it is proposed to exacerbate hypersensitivity throughout modulation of this receptor. The exact molecular mechanism by which $\mathrm{BH} 4$ induces pronociceptive effects is not fully elucidated. TNF- $\alpha$, tumor necrosis factor alpha; IL-1 $\beta$, interleukin-1beta; IFN- $\gamma$, interferon gamma; Glu, glutamate.

(Hirakawa et al., 2009; Werner et al., 2011). Finally, the recycling pathway represents a mechanism that preserves energy and generates large quantities of pterin in high-BH4 demanding organs (e.g., hepatic metabolism of aromatic amino acids). After BH4 participates as a mandatory enzymatic cofactor, the unstable intermediate $4 a$-hydroxy-tetrahydrobiopterin is formed and undergoes a dehydration leading to the formation of quinonoid dihydrobiopterin, which is reduced back to $\mathrm{BH} 4$ by dihydropteridine reductase (Thöny et al., 2000; Longo, 2009).

Increased levels of $\mathrm{BH} 4$ are expected under cellular stress and requires the production of new blocks of $\mathrm{BH} 4$. GTPCH, the rate-limiting enzyme of the de novo $\mathrm{BH} 4$ pathway, is an inducible enzyme, having its expression controlled by proinflammatory mediators, such as interferon gamma (IFN- $\gamma$ ), tumor necrosis factor alpha (TNF- $\alpha$ ), interleukin-1beta (IL-1 $\beta$ ), and lipopolysaccharides (LPS) (Werner et al., 1990). During the pro-inflammatory response, expression of GCH1 (which codes for GTPCH), and GTPCH activity are markedly increased, while the downstream enzymes, PTPS and SPR, are only slightly augmented, resulting in PTPS as the rate-limiting enzyme of the $\mathrm{BH} 4$ de novo pathway during inflammation. Consequently, this pseudometabolic blockage favors the accumulation of the PTPS substrate, which non-enzymatically will be transformed in neopterin, a well-established and sensitive biomarker for immune system activation, and for the activation of the de novo $\mathrm{BH} 4$ pathway (for a review see Ghisoni et al., 2015a; Figure 2).

\section{BH4 AND CHRONIC PAIN}

The first human validation linking chronic pain to the $\mathrm{BH} 4$ metabolism comes from the identification of single nucleotide polymorphisms in the GCH1 loci, which correlated with reduced experimental and clinical persistent pain sensitivity (Tegeder et al., 2006, 2008). Human homozygous haplotypes were associated with decreased upregulation of GCH1 upon inflammatory stimulation, but without full loss of function of GTPCH, which would preserve baseline BH4 concentrations (Campbell et al., 2009; Doehring et al., 2009; Dabo et al., 2010; Kim et al., 2010, 2013). Indeed, it was demonstrated that this human protective-pain haplotype only influences nociceptive thresholds after pain sensitization (Tegeder et al., 2008). In addition, individuals carrying the homozygous from of the haplotype are less sensitive to persistent leg pain after discectomy or persistent pain in fibromyalgia (Tegeder et al., 2008; Kim et al., 2010, 2013). However, other studies demonstrated that carrying this human homozygous polymorphism does not protect from pancreatic pain, post dental surgery or post mastectomy pains, suggesting that the association between GCH1 and pain may be disease- or tissue-specific (Kim and Dionne, 2007; Lazarev et al., 2008; Holliday et al., 2009; Hickey et al., 2011).

In rodent models, the genetic ablation of Gch1 in DRGs generated evidence supporting the contribution of excessive 


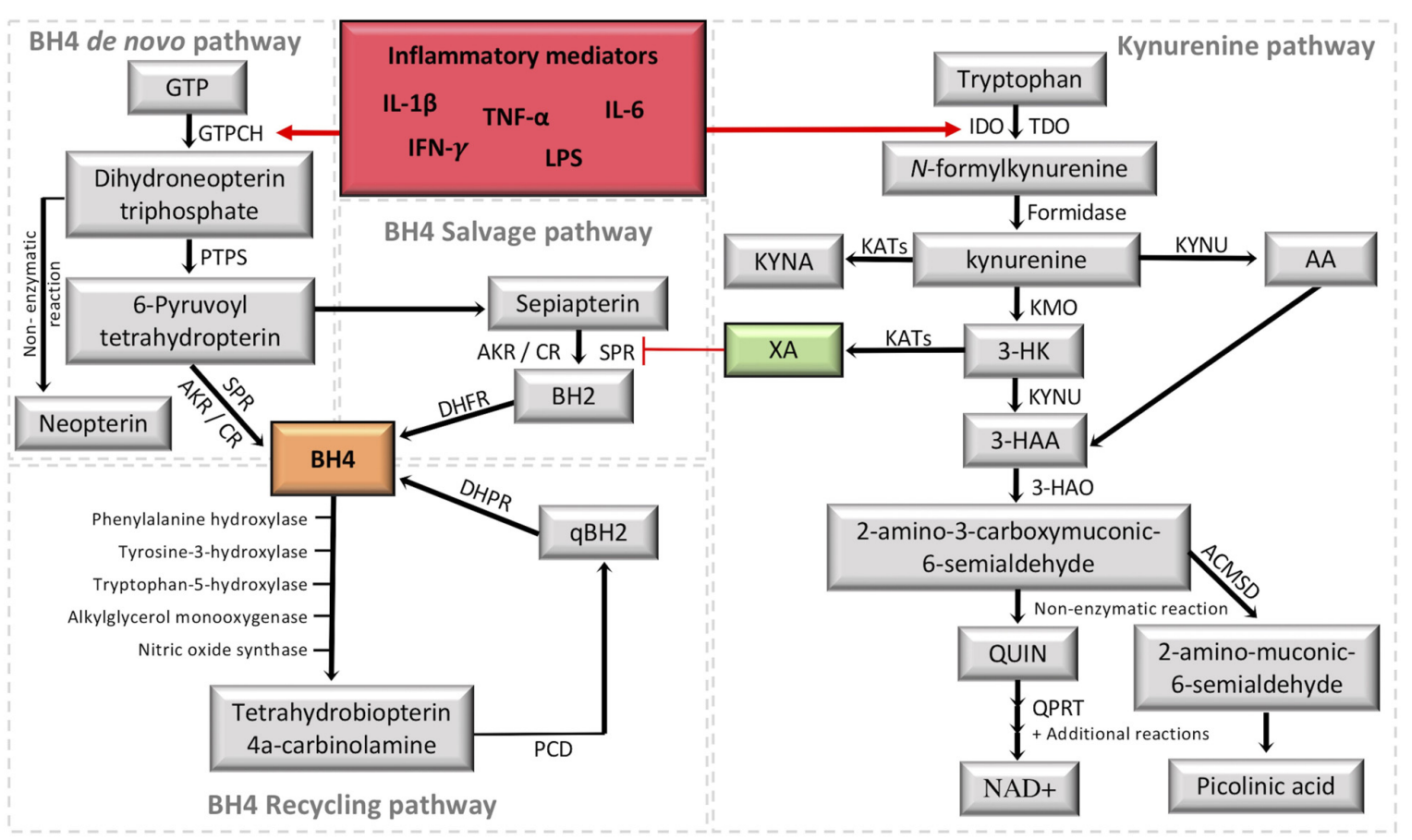

FIGURE 2 | Crosstalk between the tetrahydrobiopterin $(\mathrm{BH} 4)$ and kynurenine $(\mathrm{KYN})$ pathways. It is highlighted in red the activation of the two metabolic pathways under inflammation. It is highlighted in green the KYN intermediate xanthurenic acid (XA), which recently was demonstrated to be an inhibitor of sepiapterina reductase (SPR) (Haruki et al., 2016). The formation of BH4 (highlighted in orange) by the de novo pathway involves the catalytic activity of GTPCH (guanosine triphosphate cyclohydrolase I), PTPS (followed by 6-pyruvoyl tetrahydropterin synthase) and SPR (sepiapterin reductase). SPR deficiencies may be overcome in target tissues by unspecific reductases of the salvage pathway, including aldoketo and carbonyl reductases (AKR; CR) (Hirakawa et al., 2009; Werner et al., 2011), which transform 6-pyruvoyl-tetrahydropterin into sepiapterin and BH2 (7,8-dihydrobiopterin), then the final reduction back to BH4 is performed by DHFR (dihydrofolate reductase). The recycling pathway maintains high levels of $\mathrm{BH} 4$ in the liver, where it is mainly used to metabolize phenylalanine. After $\mathrm{BH} 4 \mathrm{oxidation}$, PCD (Pterin 4a-carbinolamine dehydratase) forms qBH2 (quinonoid dihydrobiopterin) to be reduced back to BH4 by DHPR (dihydropteridine reductase). The KYN pathway transforms tryptophan into a series of intermediates with different properties by combining the activity of several enzymes in different cells/tissues. The central intermediate KYN allows the production of XA, which inhibits SPR activity in the BH4 pathway. GTP, guanosine triphosphate; IDO1, indoleamine 2,3-dioxygenase; TDO, tryptophan 2,3-dioxygenase; KYNU, kynureninase; KYNA, kynurenic acid; KATs, kynurenine aminotransferases; KMO, kynurenine 3-monooxygenase; 3-HK, 3-hydroxykynurenine; AA, anthranilic acid; 3-HAA, 3-hydroxyanthranilic acid; 3-HAO, 3-hydroxyanthranilic acid 3,4-dioxygenase; QUIN, quinolinic acid; QPRT, quinolinate phosphoribosyltransferase; $\mathrm{NAD}^{+}$, nicotinamide adenine dinucleotide; ACMSD, 2-amino-3-carboxymuconate-6-semialdehyde decarboxylase; IFN- $\gamma$, interferon gamma, TNF- $\alpha$, tumor necrosis factor alpha; IL-1 $\beta$, interleukin 1beta; IL-6, interleukin-6; LPS, lipopolysaccharides.

levels of $\mathrm{BH} 4$ in chronic pain hypersensitivity (Kim et al., 2009; Latremoliere et al., 2015). DRG Gch1 null rats showed decreased mechanical pain hypersensitivity and microglial activation in the dorsal horn 14 days following spared nerve injury (SNI) (Kim et al., 2009). Similarly, the absence of Gch1 in the DRG of mice prevented excessive BH4 production in sensory neurons and mechanical pain hypersensitivity induced by nerve injury following 21 days of SNI and chronic constriction injury (CCI) as measured by the normalization of the mechanical threshold for pain (Latremoliere et al., 2015).

Expression and functional profiling in rodents has shown that enhanced BH4 biosynthetic enzymes transcription and activity in sensory neurons and immune cells lead to increased BH4 levels, which results in greater chronic pain hypersensitivity (Tegeder et al., 2006; Kim et al., 2009; Latremoliere et al., 2015; Cronin et al., 2018). For example, Gch1 and Spr were upregulated up to sixfold 21 days after SNI, indicating that elevated transcription for $\mathrm{BH} 4$ biosynthesis persists for some time after injury (Tegeder et al., 2006; Kim et al., 2009; Latremoliere et al., 2015). In parallel with persistent mechanical hypersensitivity, BH4 levels are increased in rat sensory neurons in response to both axonal injury and peripheral inflammation induced by SNI and intraplantar complete Freund's adjuvant (CFA) injection, respectively (Tegeder et al., 2006). Furthermore, enhanced $\mathrm{GCH} 1$ transcription and increased $\mathrm{BH} 4$ levels were identified not only in injured sensory neurons, but also in leukocytes that infiltrated the tissue after SNI in mice, which underline the contribution of the immune system in the persistence of hypersensitivity induced by BH4 overproduction (Latremoliere et al., 2015). Collectively, the enhanced expression of the transcripts for the $\mathrm{BH} 4$ biosynthetic enzymes and increased BH4 levels correlate with the persistence of mechanical and cold hypersensitivity in rat and mice models for inflammatory and neuropathic pain, reinforcing the contribution of excessive levels of BH4 with chronic pain hypersensitivity (Tegeder et al., 2006; Latremoliere et al., 2015; Fujita et al., 2019). 
TABLE 1 | Half maximal inhibitory concentration $\left(\mathrm{IC}_{50}\right)$ for the known sepiapterin reductase inhibitors (SPRi).

\begin{tabular}{|c|c|c|c|}
\hline \multirow[t]{3}{*}{ Compounds } & \multicolumn{3}{|c|}{$I_{50}$ value $(\mu M)$} \\
\hline & \multicolumn{2}{|c|}{ In vitro } & \multirow[t]{2}{*}{ In vivo } \\
\hline & $\begin{array}{l}\text { Protein-based } \\
\text { assay }\end{array}$ & $\begin{array}{l}\text { Cellular } \\
\text { system }\end{array}$ & \\
\hline \multicolumn{4}{|l|}{ Natural SPRi } \\
\hline \multirow[t]{6}{*}{$\mathrm{N}$-acetyl-serotonin } & $3.8^{h}$ & $\varnothing$ & $\varnothing$ \\
\hline & $35^{\mathrm{m}}$ & & \\
\hline & $1.2^{r}$ & & \\
\hline & (Haruki et al., 2016) & & \\
\hline & $11.61^{\mathrm{h}}$ & & \\
\hline & (Moore et al., 2019) & & \\
\hline \multirow[t]{4}{*}{ Xanthurenic acid } & $0.15^{\mathrm{h}}$ & $\varnothing$ & $\emptyset$ \\
\hline & $0.053^{m}$ & & \\
\hline & $0.045^{r}$ & & \\
\hline & (Haruki et al., 2016) & & \\
\hline \multicolumn{4}{|l|}{ Synthetic SPRi } \\
\hline \multirow[t]{2}{*}{ SPRi3 } & $0.053^{h}$ & $0.45^{\mathrm{a}}$ & $\varnothing$ \\
\hline & (Haruki et al., 2016) & $\begin{array}{l}\text { Latremoliere } \\
\text { et al., } 2015\end{array}$ & \\
\hline \multirow[t]{3}{*}{ QM385 } & $\emptyset$ & $0.036^{b}$ & $\emptyset$ \\
\hline & & $0.074^{c}$ & \\
\hline & & $\begin{array}{l}\text { Cronin } \\
\text { et al., } 2018\end{array}$ & \\
\hline \multirow[t]{4}{*}{ Q-1195 } & $0.008^{h}$ & $\emptyset$ & $2.2^{d}$ \\
\hline & $0.004^{r}$ & & \\
\hline & Meyer et al., 2019 & & \\
\hline & & & $\begin{array}{l}\text { (Meyer } \\
\text { et al., 2019) }\end{array}$ \\
\hline \multicolumn{4}{|l|}{ FDA-approved } \\
\hline \multirow[t]{6}{*}{ Sulfasalazine } & $0.0070^{h}$ & $\varnothing$ & $\emptyset$ \\
\hline & $0.0078^{m}$ & & \\
\hline & $0.043^{r}$ & & \\
\hline & (Haruki et al., 2016) & & \\
\hline & $0.023^{h}$ & & \\
\hline & (Haruki et al., 2013) & & \\
\hline \multirow[t]{2}{*}{ Tranilast } & $5.889^{h}$ & $\varnothing$ & $\varnothing$ \\
\hline & (Moore et al., 2019) & & \\
\hline
\end{tabular}

Values are mean of at least 2 independent experiments. $\emptyset$, not determined. $h$, human SPR; $m$, mouse SPR; r, rat SPR. a, mouse primary dorsal root ganglia cell culture. b, mouse splenocytes cell culture. c, human peripheral blood mononuclear cell culture. d, adult male Sprague-Dawley rats after spinal nerve injury. FDA, Food and Drug Administration.

\section{Inhibition of Pathological BH4 Levels as a Novel Pathway to Induce Analgesia}

One of the most effective current pharmacological therapies for controlling certain types of pain is the use of opioids. However, chronic opioid use lacks safety, effectiveness and has a substantial liability for abuse and high risk of death from overdose (NIDA, 2020). Therefore, the inhibition of inflammation-triggered $\mathrm{BH} 4$ production may represent an innovative and non-addictive strategy for managing persistent pain.
Analgesia induced by the pharmacological inhibition of GTPCH activity was demonstrated in rodents subjected to SNI and CCI. The use of 2,4-diamino-6-hydroxypyrimidine (DAHP; a GTPCH inhibitor) reversed the mechanical and cold hypersensitivity induced by the nerve injury (Tegeder et al., 2006). Similarly, DAHP treatment reduced tumorevoked microglial activation in the spinal cord and reduced cancer-induced systemic hyperalgesia in mice (Pickert et al., 2012). These initial data indicated that targeting the flux of this metabolic pathway could represent new horizons in the clinical management of chronic pain. However, since GTPCH activity is essential for $\mathrm{BH} 4$ production, any pharmacological approaches should aim to reduce exacerbated $\mathrm{BH} 4$ levels back to basal levels, without compromising its physiological roles on endothelial function and metabolisms of neurotransmitters, lipids and nitric oxide.

A yeast three hybrid screen revealed that a Food and Drug Administration (FDA)-approved anti-inflammatory compound, sulfasalazine (SSZ), is an inhibitor of the $\mathrm{BH} 4$ synthesizing enzyme SPR (Haruki et al., 2013). The use of SSZ in mice subjected to SNI showed reduced mechanical pain hypersensitivity, without compromising essential BH4-related functions (Latremoliere et al., 2015). However, the analgesia induced was mild, probably due to the limited bioavailability, low potency, and complex metabolism of this drug in the gut (Pieniaszek and Bates, 1979). Thus, using a structurebased design, our group has developed new more potent SPR inhibitors (SPRi), SPRi3 and QM385. These SPRi have been shown to induce potent analgesic effects in neuropathic and inflammatory pain models, without inducing tolerance or adverse effects (Latremoliere et al., 2015; Fujita et al., 2019). Either a single or repeated SPR inhibitor intraperitoneal injection alleviated intraplantar CFA injection-, SNI-, and CCI-induced pain hypersensitivity in mice, with a maximal activity $1 \mathrm{~h}$ after the administration (Latremoliere et al., 2015). The analgesic effect of these SPRi were also demonstrated in the chronic phase of the collagen antibody-induced arthritis (CAIA) model of inflammatory joint pain, in which a rapid onset of clinical signs of arthritis is followed by a persistent pain-related hypersensitivity syndrome lasting at least 55 days (Fujita et al., 2019). We also demonstrated that SPRi reduced pain scores in mice submitted to a colitis experimental model, and that this effect was in part due to the absolute requirement of $\mathrm{T}$ cells for $\mathrm{BH} 4$ in order to expand and infiltrate tissues (Cronin et al., 2018). Another FDA-approved drug, Tranilast - an anti-allergic agent, was also demonstrated to inhibit SPR in protein- and cell-based assays (Moore et al., 2019) and to reduce pelvic pain caused by endometriosis in a clinical study (Honda et al., 2013).

Table 1 summarizes the half maximal inhibitory concentration $\left(\mathrm{IC}_{50}\right)$ values of key SPRi, including the natural SPR inhibitors (e.g., $\mathrm{N}$-acetyl-serotonin), the synthetic and FDA-approved compounds.

\section{Sepiapterin as a Biological Marker for the Analgesic Effects of SPRi}

Sepiapterin is a metabolic intermediate of the $\mathrm{BH} 4$ salvage pathway. It does not accumulate intracellularly, but is found 
at increased concentrations in the biological fluids of patients affected by mutations in the SPR gene (Carducci et al., 2015). The chemical stability of sepiapterin and its accumulation upon genetic and/or pharmacological manipulation of SPR make this metabolite a sensitive and specific biological marker of SPR inhibition (Fujita et al., 2019). Indeed, a dose-dependent increase of sepiapterin levels in plasma and urine from rodents, and humans were observed after the administration of SPRi (SSZ, SPRi3, QM385, and Q1195 in rodents and SSZ in humans (Latremoliere et al., 2015; Fujita et al., 2019; Meyer et al., 2019). In a recent publication by our group, the urinary sepiapterin was established as a reliable biomarker of SPR inhibition with high sensitivity (70-85\%) and specificity $(82-88 \%)$ in both mice and human health volunteers after the administration of SPRi3 and SSZ, respectively (Fujita et al., 2019).

In an effort to associate changes of sepiapterin and $\mathrm{BH} 4$ with analgesic effects induced by SPRi, Table 2 shows the changes on sepiapterin and BH4 levels identified in biological samples after treatment with different SPRi and the correspondent analgesic effects in different experimental pain models.

\section{THE KYN PATHWAY BIOSYNTHESIS}

The KYN pathway is active in a variety of different tissues, but more notably in the liver through the enzyme tryptophan 2,3-dioxygenase (TDO); and in cells of the immune and nervous systems (including neurons, microglia and astrocytes) by indoleamine 2,3-dioxygenase 1 (IDO1) (Moroni et al., 1988a). IDO1 is the rate-limiting enzyme of the pathway in immune cells, playing key roles in immune system activation and regulation (Guillemin et al., 2005). The most potent activator of IDO1 is IFN- $\gamma$ (Werner-Felmayer et al., 1989), but this enzyme is also activated by other mediators such as LPS, amyloid peptides, cytotoxic T lymphocyte antigen-4 (CTLA4) and HIV proteins (Guillemin et al., 2003; Jones et al., 2015). Around 95\% of the dietary tryptophan (Trp) is metabolized into the KYN pathway, which can follow three different metabolic routes, synthesizing the essential cofactor nicotinamide adenine dinucleotide $\left(\mathrm{NAD}^{+}\right.$), kynurenic acid (KYNA), or xanthurenic acid (XA) (Beadle et al., 1947; Wolf, 1974; Figure 2).

Initially, Trp can be oxidized into the instable metabolite $\mathrm{N}$-formyl-kynurenine by TDO or IDO1, to be further transformed into KYN, the central intermediate of the pathway, by formamidase. KYN can be metabolized into anthranilic acid or KYNA by kynureninase and kynurenine aminotransferases (KATs I, II, and III), respectively. Additionally, kynurenine 3-monooxygenase (KMO) can transform KYN into 3-hydroxykynurenine (3-HK) to produce 3-hydroxyanthranilic acid (3-HAA) by kynureninase. 3-HAA in turn, forms picolinic acid, QUIN and $\mathrm{NAD}^{+}$through the action of additional enzymes. 3-HK can be also metabolized by KATs into XA (Figure 2).

\section{KYN PATHWAY AND CHRONIC PAIN}

There is extensive evidence in literature that proinflammatory stimuli, mitochondrial dysfunction, oxidative stress, and the formation of neuroactive metabolites that can modulate glutamatergic receptors and neurotransmitter production are relevant to pain sensation (Moroni et al., 1988b; Turski et al., 1988). Several of the KYN pathway metabolites are neuroactive compounds able to regulate, for example, the activity of glutamatergic $\mathrm{N}$-methyl-d-aspartate (NMDA) receptors inducing toxicity, favoring the excessive generation of reactive species (Stone and Perkins, 1981; Kessler et al., 1989), or compromising the activity of the energy metabolism by deficiencies in the synthesis of Trp-linked NAD ${ }^{+}$(Massudi et al., 2012; Gomes et al., 2013; Zhu et al., 2015). For example, QUIN is a potent NMDA receptor agonist, which at nM levels induces excitotoxicity, mitochondrial damage, oxidative stress, destabilization of the cellular cytoskeleton, and disruption of autophagy, among other negative effects (Schwarcz et al., 1984; Guillemin, 2012). Thus, perturbations on the KYN pathway may favor the transition from acute to persistent pain by inducing these deleterious reactions. In this scenario, it is well established that glutamatergic neurotransmission is essential for peripheral (Pardutz et al., 2012) and central sensitization (Latremoliere and Woolf, 2009). Thus, the pharmacological antagonism of NMDA receptors has been explored as a key therapeutic target in pain disorders (Nasstrom et al., 1992; Chapman and Dickenson, 1995; Bannister et al., 2017).

It has been also demonstrated that increased IDO1 activity is inversely related to serotonin concentrations in human plasma (Lood et al., 2015), which has a relevant role in the pain inhibitory descendant modulation (Mico et al., 1997; Sawynok et al., 2001). Sustained Trp catabolism throught KYN pathway during chronic inflammation can compromise the availability of this aromatic amino acid to form serotonin, and thus decrease the serotonin inhibitory descendant pain modulation (Capuron and Dantzer, 2003; Kim et al., 2012). In line with this, a persistent mechanical and thermal hyperalgesia has been shown to be associate with a decreased serotonin/Trp ratio, and an increased KYN/Trp ratio in the hippocampus of rats under chronic arthritis inflammatory pain model induced by a joint CFA injection (Kim et al., 2012).

Clinical and preclinical studies have also demonstrated that the excessive IDO1 activation contributes to inflammationinduced pain (Kim et al., 2012; Huang et al., 2016). IDO1 expression is increased in several inflammatory and pain conditions, for example in the lungs and lymphoid tissue of mice with mechanical pain hypersensitivity induced by an acute and a chronic viral infection, respectively (Huang et al., 2016). In contrast, virus-induced mechanical pain hypersensitivity was not evident in mice lacking IDO1 genes (Huang et al., 2016). In a separate study of chronic arthritis inflammatory pain model, the IDO1 gene expression, protein content and activity were elevated in the hippocampus of rats, resulting in persistent pain hypersensitivity after 21 days of the CFA injection in the tibiotarsal joint (Kim et al., 2012). Blockage of IDO1 with the inhibitor 1-methyl-tryptophan (1-MT) attenuated persistent mechanical and thermal hyperalgesia in rats with chronic arthritis inflammatory pain (Kim et al., 2012). In a clinical observational study, patients affected with chronic back pain showed elevated plasma IDO1 and increased KYN/Trp ratio as compared with healthy controls (Kim et al., 2012). 
TABLE 2 | Analgesic effects, tetrahydrobiopterin (BH4) and sepiapterin changes for the main sepiapterin reductase inhibitors (SPRi).

\begin{tabular}{|c|c|c|c|c|}
\hline SPRi & Analgesic effect & Experimental pain model & BH4 changes & Sepiapterin changes \\
\hline \multirow[t]{2}{*}{$\begin{array}{l}\mathrm{N} \text {-acetyl- } \\
\text { serotonin }\end{array}$} & $\begin{array}{l}\Downarrow \text { Cold allodynia; } \Downarrow \text { Mechanical allodynia (Tegeder } \\
\text { et al., 2006) }\end{array}$ & Spared nerve injury neuropathic pain model & $\emptyset$ & $\emptyset$ \\
\hline & $\Downarrow$ Heat hyperalgesia (Tegeder et al., 2006) & $\begin{array}{l}\text { Granulomatous skin inflammatory pain model } \\
\text { (intra-plantar injection of CFA) }\end{array}$ & $\emptyset$ & $\emptyset$ \\
\hline \multirow[t]{3}{*}{ SPRi3 } & $\begin{array}{l}\Downarrow \text { Heat hyperalgesia; } \Downarrow \text { Mechanical allodynia (Fujita } \\
\text { et al., 2019) }\end{array}$ & Collagen antibody-induced arthritis model & $\Downarrow$ in urine & $\Uparrow$ in urine \\
\hline & $\Downarrow$ Mechanical allodynia (Latremoliere et al., 2015) & $\begin{array}{l}\text { Chronic constriction injury and spared nerve } \\
\text { injury neuropathic pain models }\end{array}$ & $\begin{array}{l}\Downarrow \text { in DRG, } \\
\text { sciatic nerve } \\
\text { and plasma }\end{array}$ & $\begin{array}{l}\Uparrow \text { in DRG, sciatic nerve } \\
\text { and plasma }\end{array}$ \\
\hline & $\begin{array}{l}\Downarrow \text { Heat hyperalgesia; No changes in mechanical } \\
\text { allodynia (Latremoliere et al., 2015) }\end{array}$ & $\begin{array}{l}\text { Granulomatous skin inflammatory pain model } \\
\text { (intraplantar injection of CFA) }\end{array}$ & $\begin{array}{l}\Downarrow \text { in plantar } \\
\text { skin }\end{array}$ & $\emptyset$ \\
\hline QM385 & $\Downarrow$ Heat hyperalgesia (Fujita et al., 2019) & Collagen antibody-induced arthritis model & $\emptyset$ & $\Uparrow$ in plasma \\
\hline Q-1195 & $\begin{array}{l}\text { No changes in mechanical allodynia (Meyer et al., } \\
\text { 2019) }\end{array}$ & Spinal nerve ligation neuropathic pain model & $\Downarrow$ in DRG & $\Uparrow$ in plasma and $\mathrm{DRG}$ \\
\hline Sulfasalazine & $\Downarrow$ Mechanical allodynia (Latremoliere et al., 2015) & Spared nerve injury neuropathic pain model & $\varnothing$ & $\Uparrow$ in plasma \\
\hline
\end{tabular}

$\emptyset$ not evaluated. CFA, complete Freund's adjuvant; DRG, dorsal root ganglia.

In murine pre-clinical models, alterations in the KYN pathway and immune system contributing to pain hypersensitivity were demonstrated. For example, in sensory neurons from the DRG and spinal cord, sustained IDO1 and KMO activation due to nerve injury were associated with mechanical and thermal hypersensitivity in rats after 21 the CCI in the sciatic nerve (Rojewska et al., 2016, 2018). Furthermore, in cell culture models we demonstrated that the overexpression of KMO, and subsequent increase in QUIN production is mainly enhanced in monocytic cells, including macrophages and microglia during inflammation (Guillemin et al., 2003). Indeed, the administration of the microglial inhibitor minocycline was able to reduce mechanical hypersensitivity in parallel with a reduction of KMO expression in sensory neurons from rat submitted to the chronic neuropathic pain model induced by the CCI (Rojewska et al., 2014a, 2016). Similarly, treatment with inhibitors for IDO1 (1-MT) or KMO (Ro61-6048 and JM6) attenuated the persistent mechanical and thermal hypersensitivity, along with reduced markers of peripheral inflammation in rat the model of chronic neuropathic pain induced by the sciatic nerve CCI (Rojewska et al., 2016, 2018). These evidence strengthens the correlation between upregulation of KYN pathway, dysregulation of immune system and the development of persistent pain hypersensitivity.

\section{$\mathrm{XA}$, the Link Between the BH4 Metabolism and the KYN Pathway in Pain}

$\mathrm{XA}$ was identified as a potent inhibitor of SPR during a screening of a collection of natural compounds (Haruki et al., 2016). This implies that this KYN pathway metabolite has potential to limit the pathological overproduction of $\mathrm{BH} 4$ observed in experimental pain models, and therefore induce similar analgesic effects as those elicited by synthetic SPRi, SPRi3 and QM385.

A role for XA in neurotransmission and neuromodulation has been suggested based on (i) the capacity to cross the BBB and spread heterogeneously within different mouse brain regions (Gobaille et al., 2008); (ii) the inhibitory effect on the rat brain vesicular release of glutamate, reducing the glutamatergic transmission (Neale et al., 2013); and (iii) the activity as an agonist of metabotropic glutamate receptors type II, which have been implicated in the negative modulation of nociceptive transmission (Fazio et al., 2016). Thus, the better understanding of the metabolic interaction between these two pathways during inflammation may open new avenues to pharmacologically modulate chronic pain. Indeed, XA has been proposed as an antinociceptive compound, as intraperitoneal administration of $\mathrm{XA}$ increased the threshold for nociception in rats (Heyliger et al., 1998) and lower levels of plasma XA were observed in patients affected by episodic and chronic cluster headache in a clinical observational study (Curto et al., 2016). However, to the best of our knowledge, XA-induced decreased SPR activity in a cellular system or a correlation between analgesic effects and SPR inhibition have not been explored yet.

\section{CONCLUSION}

Advances in the understanding of the mechanisms behind the development of chronic pain have identified a critical interaction between the immune system and the nervous system. These two systems synergistically promote local and systemic responses that restore homeostasis after tissue injury and/or infection. However, this bidirectional communication is also involved in maladaptive feedforward inflammatory loops at multiple levels of the neuroaxis contributing to the development of chronic pain. Neuro-immune interactions are able to control the metabolic flux of various metabolic pathways, including the BH4 and KYN pathways. Both are rapidly activated by inflammation, resulting in the production of several biologically active metabolites, which have been involved in pain states. Recently, XA, a KYN pathway intermediate, was identified as an endogenous inhibitor of the BH4 metabolism. This raises the possibility that XA can potentially modulate the pathological 
overproduction of $\mathrm{BH} 4$ reported in chronic pain hypersensitivity experimental models. The modulation of the KYN pathway can be directed toward the production of XA (through the kynureninase inhibition e.g.), resulting in alterations of $\mathrm{BH} 4$. Therefore, understanding the interaction between these two pathways during inflammation is likely to open new avenues to pharmacologically modulate chronic pain.

Altogether, strategies aiming to manipulate the production of bioactive metabolites from the $\mathrm{BH} 4$ and KYN pathways, especially in sensory neurons, immune and glia cells might represent promising new analgesic approaches to reduce the hypersensitivity triggered by chronic inflammation. However, given the major central functions of the metabolites produced through the $\mathrm{BH} 4$ and KYN pathways in physiological conditions, potential undesirable side effects could be triggered by therapeutic approaches involving the manipulation of both pathways. The relationship between $\mathrm{BH} 4$ and $\mathrm{KYN}$ pathways, and especially its possible relevance for inflammation-induced pain hypersensitivity, should be critically assessed, and preclinical experiments exploring the complex interconnection between both pathways and the production of clinical evidence are encouraged.

\section{REFERENCES}

Bannister, K., Kucharczyk, M., and Dickenson, A. H. (2017). Hopes for the future of pain control. Pain Ther. 6, 117-128. doi: 10.1007/s40122-0170073-6

Beadle, G. W., Mitchell, H. K., and Nyc, J. F. (1947). Kynurenine as an intermediate in the formation of nicotinic acid from tryptophane by neurospora. Proc. Natl. Acad. Sci. U.S.A. 33, 155-158. doi: 10.1073/pnas.33.6.155

Beringer, A., and Miossec, P. (2019). Systemic effects of IL-17 in inflammatory arthritis. Nat. Rev. Rheumatol. 15, 491-501. doi: 10.1038/s41584-019-0243-5

Breivik, H., Collett, B., Ventafridda, V., Cohen, R., and Gallacher, D. (2006). Survey of chronic pain in Europe: prevalence, impact on daily life, and treatment. Eur. J. Pain 10, 287-333.

Brueggemann, L. I., Mani, B. K., Mackie, A. R., Cribbs, L. L., and Byron, K. L. (2010). Novel actions of nonsteroidal anti-inflammatory drugs on vascular ion channels: accounting for cardiovascular side effects and identifying new therapeutic applications. Mol. Cell Pharmacol. 2, 15-19.

Busse, J. W., Wang, L., Kamaleldin, M., Craigie, S., Riva, J. J., Montoya, L., et al. (2018). Opioids for chronic noncancer pain: a systematic review and meta-analysis. JAMA 320, 2448-2460.

Campbell, C. M., Edwards, R. R., Carmona, C., Uhart, M., Wand, G., Carteret, A., et al. (2009). Polymorphisms in the GTP cyclohydrolase gene (GCH1) are associated with ratings of capsaicin pain. Pain 141, 114-118. doi: 10.1016/j. pain.2008.10.023

Capuron, L., and Dantzer, R. (2003). Cytokines and depression: the need for a new paradigm. Brain Behav. Immun. 17(Suppl. 1), S119-S124.

Carducci, C., Santagata, S., Friedman, J., Pasquini, E., Carducci, C., Tolve, M., et al. (2015). Urine sepiapterin excretion as a new diagnostic marker for sepiapterin reductase deficiency. Mol. Genet. Metab. 115, 157-160. doi: 10.1016/j.ymgme. 2015.06.009

Chapman, V., and Dickenson, A. H. (1995). Time-related roles of excitatory amino acid receptors during persistent noxiously evoked responses of rat dorsal horn neurones. Brain Res. 703, 45-50. doi: 10.1016/0006-8993(95) 01063-7

Chayadi, E., and Mcconnell, B. L. (2019). Gaining insights on the influence of attention, anxiety, and anticipation on pain perception. J. Pain Res. 12, 851-864. doi: $10.2147 /$ jpr.s176889

\section{AUTHOR CONTRIBUTIONS}

AS designed the concept and drafted the manuscript. AL, GG, VT, and $\mathrm{BH}$ reviewed and edited the manuscript. All authors listed have made a substantial, direct and intellectual contribution to the work, and approved it for publication.

\section{FUNDING}

AS is supported by CAPES (Coordenação de Aperfeiçoamento de Pessoal de Nível Superior) and Cotutelle "iMQRES" (International Cotutelle Macquarie University Research Exellence) scholarships. AL is a CNPq (Conselho Nacional de Desenvolvimento Cientiìfico e Tecnoloìgico) fellow. GG, VT, and $\mathrm{BH}$ are supported by the National Health and Medical Research Council, The Australian Research Council and Macquarie University.

\section{ACKNOWLEDGMENTS}

This manuscript has been professionally edited by Redfern Communication, Australia.

Chou, R., Deyo, R., Devine, B., Hansen, R., Sullivan, S., Jarvik, J. G., et al. (2014). The effectiveness and risks of long-term opioid treatment of chronic pain. Evid. Rep. Technol. Assess. (Full Rep.) 218, 1-219.

Christianson, C. A., Dumlao, D. S., Stokes, J. A., Dennis, E. A., Svensson, C. I., and Corr, M. (2011). Spinal TLR4 mediates the transition to a persistent mechanical hypersensitivity after the resolution of inflammation in serum-transferred arthritis. Pain 152, 2881-2891. doi: 10.1016/j.pain.2011.09.020

Chua, J., Ishihara, S., Riad, M., Castrejon, I., Miller, R., Malfait, A.-M., et al. (2019). Peripheral and central sensitization and neuropathic pain are present in both osteoarthritis and rheumatoid arthritis. Osteoarthr. Cartil. 27:S414.

Costigan, M., Belfer, I., Griffin, R. S., Dai, F., Barrett, L. B., Coppola, G., et al. (2010). Multiple chronic pain states are associated with a common amino acid-changing allele in KCNS1. Brain 133, 2519-2527. doi: 10.1093/brain/ awq195

Costigan, M., Moss, A., Latremoliere, A., Johnston, C., Verma-Gandhu, M., and Herbert, T. A. (2009a). T-cell infiltration and signaling in the adult dorsal spinal cord is a major contributor to neuropathic pain-like hypersensitivity. J. Neurosci. 29, 14415-14422. doi: 10.1523/jneurosci.4569-09.2009

Costigan, M., Scholz, J., and Woolf, C. J. (2009b). Neuropathic pain: a maladaptive response of the nervous system to damage. Annu. Rev. Neurosci. 32, 1-32. doi: 10.1146/annurev.neuro.051508.135531

Cronin, S. J. F., Seehus, C., Weidinger, A., Talbot, S., Reissig, S., Seifert, M., et al. (2018). The metabolite BH4 controls T cell proliferation in autoimmunity and cancer. Nature 563, 564-568.

Curto, M., Lionetto, L., Negro, A., Capi, M., Perugino, F., Fazio, F., et al. (2016). Altered serum levels of kynurenine metabolites in patients affected by cluster headache. J. Headache Pain 17:27.

Dabo, F., Grönbladh, A., Nyberg, F., Sundström-Poromaa, I., and Akerud, H. (2010). Different SNP combinations in the GCH1 gene and use of labor analgesia. Mol. Pain 6:41.

Dahlhamer, J., Lucas, J., Zelaya, C., Nahin, R., Mackey, S., DeBar, L., et al. (2018). Prevalence of chronic pain and high-impact chronic pain among adults United States, 2016. MMWR Morb. Mortal. Wkly. Rep. 67, 1001-1006. doi: 10.15585/mmwr.mm6736a2

Dart, R. C., Severtson, S. G., and Bucher-Bartelson, B. (2015). Trends in opioid analgesic abuse and mortality in the United States. N. Engl. J. Med. 372, 241-248. doi: 10.1056/nejmsa1406143 
De Paula Martins, R., Ghisoni, K., Lim, C. K., Aguiar, A. S. Jr., Guillemin, G. J., and Latini, A. (2018). Neopterin preconditioning prevents inflammasome activation in mammalian astrocytes. Free Radic. Biol. Med. 115, 371-382. doi: 10.1016/j. freeradbiomed.2017.11.022

De Souza, J. B., Grossmann, E., Perissinotti, D. M. N., de Oliveira, J. O. Jr., da Fonseca, P. R. B., and de Paula Posso, I. (2017). Prevalence of chronic pain, treatments, perception, and interference on life activities: brazilian populationbased survey. Pain Res. Manag. 2017:4643830.

Doehring, A., Freynhagen, R., Griessinger, N., Zimmermann, M., Sittl, R., von Hentig, N., et al. (2009). Cross-sectional assessment of the consequences of a GTP cyclohydrolase 1 haplotype for specialized tertiary outpatient pain care. Clin. J. Pain 25, 781-785. doi: 10.1097/ajp.0b013e3181b43e12

Enthoven, W. T. M., Roelofs, P. D. D. M., Deyo, R. A., van Tulder, M. W., and Koes, B. W. (2016). Non steroidal anti inflammatory drugs for chronic low back pain. Cochrane Database Syst. Rev. 2:CD012087.

Fazio, F., Lionetto, L., Curto, M., Iacovelli, L., Cavallari, M., Zappulla, C., et al. (2016). Xanthurenic acid activates mGlu2/3 metabotropic glutamate receptors and is a potential trait marker for schizophrenia. Sci. Rep. 5:17799.

Fujita, M., da Luz Scheffer, D., Turnes, B. L., Cronin, S. J. F., Latrémolière, A., and Costigan, M. (2019). Sepiapterin reductase inhibition selectively reduces inflammatory joint pain and increases urinary sepiapterin. Arthr. Rheumatol. 72, 57-66. doi: 10.1002/art.41060

Gao, Y. J., and Ji, R. R. (2010). Chemokines, neuronal-glial interactions, and central processing of neuropathic pain. Pharmacol. Ther. 126, 56-68. doi: 10.1016/j. pharmthera.2010.01.002

Gereau, R. W. IV, Sluka, K. A., Maixner, W., Savage, S. R., Price, T. J., Murinson, B. B., et al. (2014). A pain research agenda for the 21 st century. J. Pain 15, 1203-1214.

Ghisoni, K., Aguiar, A. S. Jr., de Oliveira, P. A., Matheus, F. C., Gabach, L., Perez, M., et al. (2016). Neopterin acts as an endogenous cognitive enhancer. Brain Behav. Immun. 56, 156-164. doi: 10.1016/j.bbi.2016.02.019

Ghisoni, K., de Paula Martins, R., Barbeito, L., and Latini, A. (2015a). Neopterin as a potential cytoprotective brain molecule. J. Psychiatr. Res. 71, 134-139. doi: 10.1016/j.jpsychires.2015.10.003

Ghisoni, K., Latini, A., Kuehne, L. K., Reiber, H., Bechter, K., Hagberg, L., et al. (2015b). Cerebrospinal fluid neopterin is brain-derived and not associated with blood-CSF barrier dysfunction in non-inflammatory affective and schizophrenic spectrum disorders. J. Psychiatr. Res. 63, 141-142. doi: 10.1016/j.jpsychires.2015.02.002

Gobaille, S., Kemmel, V., Brumaru, D., Dugave, C., Aunis, D., and Maitre, M. (2008). Xanthurenic acid distribution, transport, accumulation and release in the rat brain. J. Neurochem. 105, 982-993. doi: 10.1111/j.1471-4159.2008. 05219.x

Gomes, A. P., Price, N. L., Ling, A. J. Y., Moslehi, J. J., Montgomery, M. K., Rajman, L., et al. (2013). Declining $\mathrm{NAD}(+)$ induces a pseudohypoxic state disrupting nuclear-mitochondrial communication during aging. Cell 155, 1624-1638. doi: 10.1016/j.cell.2013.11.037

Goren, A., Mould-Quevedo, J., and Dacosta Dibonaventura, M. (2014). Prevalence of pain reporting and associated health outcomes across emerging markets and developed countries. Pain Med. 15, 1880-1891. doi: 10.1111/pme.12542

Guillemin, G. J. (2012). Quinolinic acid, the inescapable neurotoxin. FEBS J. 279, 1356-1365. doi: 10.1111/j.1742-4658.2012.08485.x

Guillemin, G. J., Smith, D. G., Smythe, G. A., Armati, P. J., and Brew, B. J. (2003). Expression of the kynurenine pathway enzymes in human microglia and macrophages. Adv. Exp. Med. Biol. 527, 105-112. doi: 10.1007/978-1-46150135-0_12

Guillemin, G. J., Smythe, G., Takikawa, O., and Brew, B. J. (2005). Expression of indoleamine 2,3-dioxygenase and production of quinolinic acid by human microglia, astrocytes, and neurons. Glia 49, 15-23. doi: 10.1002/glia.20090

Haruki, H., Hovius, R., Pedersen, M. G., and Johnsson, K. (2016). Tetrahydrobiopterin biosynthesis as a potential target of the kynurenine pathway metabolite xanthurenic acid. J. Biol. Chem. 291, 652-657. doi: 10.1074/jbc.c115.680488

Haruki, H., Pedersen, M. G., Gorska, K. I., Pojer, F., and Johnsson, K. (2013). Tetrahydrobiopterin biosynthesis as an off-target of sulfa drugs. Science 340, 987-991. doi: 10.1126/science.1232972
Heyliger, S. O., Goodman, C. B., Ngong, J. M., and Soliman, K. F. (1998). The analgesic effects of tryptophan and its metabolites in the rat. Pharmacol. Res. 38, 243-250. doi: 10.1006/phrs.1998.0362

Hickey, O. T., Nugent, N. F., Burke, S. M., Hafeez, P., Mudrakouski, A. L., and Shorten, G. D. (2011). Persistent pain after mastectomy with reconstruction. J. Clin. Anesth. 23, 482-488. doi: 10.1016/j.jclinane.2011.01.009

Hirakawa, H., Sawada, H., Yamahama, Y., Takikawa, S.-I., Shintaku, H., Hara, A., et al. (2009). Expression analysis of the Aldo-keto reductases involved in the novel biosynthetic pathway of tetrahydrobiopterin in human and mouse tissues. J. Biochem. 146, 51-60. doi: 10.1093/jb/mvp042

Holliday, K. L., Nicholl, B. I., Macfarlane, G. J., Thomson, W., Davies, K. A., and McBeth, J. (2009). Do genetic predictors of pain sensitivity associate with persistent widespread pain? Mol. Pain 5:53.

Honda, R., Honda, T., Tashiro, H., Saya, H., Yoshimura, Y., and Katabuchi, H. (2013). Evaluating the effect of tranilast for pelvic pain caused by endometriosis. Fertil. Steril. 100, S372-S373.

Huang, L., Ou, R., de Souza, G. R., Cunha, T. M., Lemos, H., Mohamed, E., et al. (2016). Virus infections incite pain hypersensitivity by inducing indoleamine 2,3 dioxygenase. PLoS Pathog. 12:e1005615. doi: 10.1371/journal.ppat.1005615

IASP (2019). Definitions of Chronic Pain Syndromes. Available online at: https: //www.iasp-pain.org/Advocacy/icd.aspx?ItemNumber=5354\#chronicpain (accessed April 30, 2020).

Inoue, S., Kobayashi, F., Nishihara, M., Arai, Y.-C. P., Ikemoto, T., Kawai, T., et al. (2015). Chronic pain in the japanese community-prevalence, characteristics and impact on quality of life. PLoS One 10:e0129262. doi: 10.1371/journal.pone. 0129262

Jones, C. M. (2017). The paradox of decreasing nonmedical opioid analgesic use and increasing abuse or dependence - an assessment of demographic and substance use trends, United States, 2003-2014. Addict Behav. 65, 229-235. doi: 10.1016/j.addbeh.2016.08.027

Jones, S. P., Franco, N. F., Varney, B., Sundaram, G., Brown, D. A., de Bie, J., et al. (2015). Expression of the kynurenine pathway in human peripheral blood mononuclear cells: implications for inflammatory and neurodegenerative disease. PLoS One 10:e0131389. doi: 10.1371/journal.pone.0131389

Kandel, E. R. (2013). Principles of Neural Science, 5th Edn. New York: McGraw-Hill Medical, 1709.

Kawasaki, Y., Zhang, L., Cheng, J.-K., and Ji, R.-R. (2008). Cytokine mechanisms of central sensitization: distinct and overlapping role of interleukin-1beta, interleukin-6, and tumor necrosis factor-alpha in regulating synaptic and neuronal activity in the superficial spinal cord. J. Neurosci. 28, 5189-5194. doi: 10.1523/jneurosci.3338-07.2008

Kessler, M., Terramani, T., Lynch, G., and Baudry, M. (1989). A glycine site associated with $\mathrm{N}$-methyl-D-aspartic acid receptors: characterization and identification of a new class of antagonists. J. Neurochem. 52, 1319-1328. doi: 10.1111/j.1471-4159.1989.tb01881.x

Kigerl, K. A., Gensel, J. C., Ankeny, D. P., Alexander, J. K., Donnelly, D. J., and Popovich, P. G. (2009). Identification of two distinct macrophage subsets with divergent effects causing either neurotoxicity or regeneration in the injured mouse spinal cord. J. Neurosci. 29, 13435-13444. doi: 10.1523/jneurosci.325709.2009

Kim, D. H., Dai, F., Belfer, I., Banco, R. J., Martha, J. F., Tighiouart, H., et al. (2010). Polymorphic variation of the guanosine triphosphate cyclohydrolase 1 gene predicts outcome in patients undergoing surgical treatment for lumbar degenerative disc disease. Spine 35, 1909-1914. doi: 10.1097/brs. 0b013e3181eea007

Kim, H., Chen, L., Lim, G., Sung, B., Wang, S., McCabe, M. F., et al. (2012). Brain indoleamine 2,3-dioxygenase contributes to the comorbidity of pain and depression. J. Clin. Invest. 122, 2940-2954. doi: 10.1172/jci 61884

Kim, H., and Dionne, R. A. (2007). Lack of influence of GTP cyclohydrolase gene $(\mathrm{GCH} 1)$ variations on pain sensitivity in humans. Mol. Pain 3:6.

Kim, S. J., Lee, W. I., Lee, Y. S., Kim, D. H., Chang, J. W., Kim, S. W., et al. (2009). Effective relief of neuropathic pain by adeno-associated virus-mediated expression of a small hairpin RNA against GTP cyclohydrolase 1. Mol. Pain 5, 67-67.

Kim, S. K., Kim, S.-H., Nah, S.-S., Lee, J. H., Hong, S.-J., Kim, H.-S., et al. (2013). Association of guanosine triphosphate cyclohydrolase 1 gene polymorphisms 
with fibromyalgia syndrome in a Korean population. J. Rheumatol. 40, 316-322. doi: 10.3899/jrheum.120929

Latini, A., de Bortoli da Silva, L., da Luz Scheffer, D., Pires, A. C. S., de Matos, F. J., and Nesi, R. T. (2018). Tetrahydrobiopterin improves hippocampal nitric oxide-linked long-term memory. Mol. Genet. Metab. 125, 104-111. doi: 10. 1016/j.ymgme.2018.06.003

Latremoliere, A., Latini, A., Andrews, N., Cronin, S. J., Fujita, M., Gorska, K., et al. (2015). Reduction of neuropathic and inflammatory pain through inhibition of the tetrahydrobiopterin pathway. Neuron 86, 1393-1406. doi: 10.1016/j. neuron.2015.05.033

Latremoliere, A., and Woolf, C. J. (2009). Central sensitization: a generator of pain hypersensitivity by central neural plasticity. J. Pain 10, 895-926. doi: 10.1016/j.jpain.2009.06.012

Laumet, G., Zhou, W., Dantzer, R., Edralin, J. D., Huo, X. J., Budac, D. P., et al. (2017). Upregulation of neuronal kynurenine 3-monooxygenase mediates depression-like behavior in a mouse model of neuropathic pain. Brain Behav. Immun. 66, 94-102. doi: 10.1016/j.bbi.2017.07.008

Lazarev, M., Lamb, J., Barmada, M. M., Dai, F., Anderson, M. A., Max, M. B., et al. (2008). Does the pain-protective GTP cyclohydrolase haplotype significantly alter the pattern or severity of pain in humans with chronic pancreatitis? Mol. Pain 4:58.

Longo, N. (2009). Disorders of biopterin metabolism. J. Inherit. Metab. Dis. 3, 333-342. doi: 10.1007/s10545-009-1067-2

Lood, C., Tydén, H., Gullstrand, B., Klint, C., Wenglén, C., Nielsen, C. T., et al. (2015). Type I interferon-mediated skewing of the serotonin synthesis is associated with severe disease in systemic lupus erythematosus. PLoS One 10:e0125109. doi: 10.1371/journal.pone.0125109

Macario, A., and Lipman, A. G. (2001). Ketorolac in the era of cyclo-oxygenase-2 selective nonsteroidal anti-inflammatory drugs: a systematic review of efficacy, side effects, and regulatory issues. Pain Med. 2, 336-351. doi: 10.1046/j.15264637.2001.01043.x

Massudi, H., Grant, R., Braidy, N., Guest, J., Farnsworth, B., and Guillemin, G. J. (2012). Age-associated changes in oxidative stress and NAD+ metabolism in human tissue. PLoS one 7:e42357. doi: 10.1371/journal.pone.0042357

Meyer, J. T., Sparling, B. A., McCarty, W. J., Zhang, M., Soto, M., Schneider, S., et al. (2019). Pharmacological assessment of sepiapterin reductase inhibition on tactile response in the rat. J. Pharmacol. Exp. Ther. 371, 476-486. doi: 10.1124/jpet.119.257105

Mico, J. A., Gibert-Rahola, J., Casas, J., Rojas, O., Serrano, M. I., and Serrano, J. S. (1997). Implication of beta 1 - and beta 2-adrenergic receptors in the antinociceptive effect of tricyclic antidepressants. Eur. Neuropsychopharmacol. 7, 139-145. doi: 10.1016/s0924-977x(97)00411-2

Miller, A., Sanderson, K., Bruno, R., Breslin, M., and Neil, A. L. (2017). The prevalence of pain and analgesia use in the Australian population: findings from the 2011 to 2012 Australian National Health Survey. Pharmacoepidemiol. Drug Safety 26, 1403-1410. doi: 10.1002/pds.4301

Mobbs, D., Marchant, J. L., Hassabis, D., Seymour, B., Tan, G., Gray, M., et al. (2009). From threat to fear: the neural organization of defensive fear systems in humans. J. Neurosci. 29, 12236-12243. doi: 10.1523/jneurosci.2378-09.2009

Moore, B. J. R., Islam, B., Ward, S., Jackson, O., Armitage, R., Blackburn, J., et al. (2019). Repurposing of tranilast for potential neuropathic pain treatment by inhibition of sepiapterin reductase in the BH4 pathway. ACS Omega 4, 11960-11972. doi: 10.1021/acsomega.9b01228

Moroni, F., Russi, P., Carlá, V., and Lombardi, G. (1988a). Kynurenic acid is present in the rat-brain and its content increases during development and aging processes. Neurosci. Lett. 94, 145-150. doi: 10.1016/0304-3940(88)90285-6

Moroni, F., Russi, P., Lombardi, G., Beni, M., and Carlà, V. (1988b). Presence of kynurenic acid in the mammalian brain. J. Neurochem. 51, 177-180. doi: 10.1111/j.1471-4159.1988.tb04852.x

Nalamachu, S. (2013). An overview of pain management: the clinical efficacy and value of treatment. Am. J. Manag. Care 19, S261-S266.

Nasstrom, J., Karlsson, U., and Post, C. (1992). Antinociceptive actions of different classes of excitatory amino-acid receptor antagonists in mice. Eur. J. Pharmacol. 212, 21-29. doi: 10.1016/0014-2999(92)90067-e

Neale, S. A., Copeland, C. S., Uebele, V. N., Thomson, F. J., and Salt, T. E. (2013). Modulation of hippocampal synaptic transmission by the kynurenine pathway member xanthurenic acid and other VGLUT inhibitors. Neuropsychopharmacology 38, 1060-1067. doi: 10.1038/npp.2013.4
NIDA, (2020). Opioid Overdose Crisis. Available online at: https://www.drugabuse. gov/drugs-abuse/opioids/opioid-overdose-crisis (accessed April 30, 2020). doi: 10.1038/npp.2013.4

Oikawa, T., Sakata, Y., Nochioka, K., Miura, M., Abe, R., Kasahara, S., et al. (2019). Increased risk of cancer death in patients with chronic heart failurewith a special reference to inflammation-A report from the Chart-2 Study. Int. J. Cardiol. 290, 106-112. doi: 10.1016/j.ijcard.2019.04.078

O'Neill, S., Ross, J. A., Wigmore, S. J., and Harrison, E. M. (2016). The role of the adaptive immune system in mediating protection from renal ischemiareperfusion injury by heat shock protein 90 inhibition. Br. J. Surg. 103:99.

Pardutz, A., Fejes, A., Bohár, Z., Tar, L., Toldi, J., and Vécsei, L. (2012). Kynurenines and headache. J. Neural Transm. (Vienna) 119, 285-296. doi: 10.1007/s00702011-0665-y

Pickert, G., Myrczek, T., Rückert, S., Weigert, A., Häussler, A., Ferreirós, N., et al. (2012). Inhibition of Gtp cyclohydrolase reduces cancer pain in mice and enhances analgesic effects of morphine. J. Mol. Med. 90, 1473-1486. doi: 10.1007/s00109-012-0927-7

Pieniaszek, H. J. Jr., and Bates, T. R. (1979). Capacity-limited gut wall metabolism of 5-aminosalicylic acid, a therapeutically active metabolite of sulfasalazine, in rats. J. Pharm. Sci. 68, 1323-1325. doi: 10.1002/jps.2600681036

Rice, A. S., Smith, B. H., and Blyth, F. M. (2016). Pain and the global burden of disease. Pain 157, 791-796. doi: 10.1097/j.pain.0000000000000454

Rojewska, E., Ciapała, K., Piotrowska, A., Makuch, W., and Mika, J. (2018). Pharmacological inhibition of indoleamine 2,3-dioxygenase-2 and kynurenine 3-monooxygenase, enzymes of the kynurenine pathway, significantly diminishes neuropathic pain in a rat model. Front. Pharmacol. 9:724. doi: 10.3389/fphar.2018.00724

Rojewska, E., Korostynski, M., Przewlocki, R., Przewlocka, B., and Mika, J. (2014a). Expression profiling of genes modulated by minocycline in a rat model of neuropathic pain. Mol. Pain 10:47.

Rojewska, E., Makuch, W., Przewlocka, B., and Mika, J. (2014b). Minocycline prevents dynorphin-induced neurotoxicity during neuropathic pain in rats. Neuropharmacology 86, 301-310. doi: 10.1016/j.neuropharm.2014.08.001

Rojewska, E., Piotrowska, A., Makuch, W., Przewlocka, B., and Mika, J. (2016). Pharmacological kynurenine 3-monooxygenase enzyme inhibition significantly reduces neuropathic pain in a rat model. Neuropharmacology 102, 80-91. doi: 10.1016/j.neuropharm.2015.10.040

Sawynok, J., Esser, M. J., and Reid, A. R. (2001). Antidepressants as analgesics: an overview of central and peripheral mechanisms of action. J. Psychiatry Neurosci. 26, 21-29.

Schwarcz, R., Foster, A. C., French, E. D., Whetsell, W. O. Jr., and Köhler, C. (1984). Excitotoxic models for neurodegenerative disorders. Life Sci. 35, 19-32. doi: 10.1016/0024-3205(84)90148-6

Shi, Y., Gelman, B. B., Lisinicchia, J. G., and Tang, S.-J. (2012). Chronicpain-associated astrocytic reaction in the spinal cord dorsal horn of human immunodeficiency virus-infected patients. J. Neurosci. 32, 10833-10840. doi: 10.1523/jneurosci.5628-11.2012

Shupler, M. S., Kramer, J. K., Cragg, J. J., Jutzeler, C. R., and Whitehurst, D. G. T. (2019). Pan-canadian estimates of chronic pain prevalence from 2000 to 2014: a repeated cross-sectional survey analysis. J. Pain 20, 557-565. doi: 10.1016/j. jpain.2018.10.010

Skljarevski, V., Liu, P., Zhang, S., Ahl, J., and Martinez, J. M. (2012). Efficacy and safety of duloxetine in patients with chronic low back pain who used versus did not use concomitant nonsteroidal anti-inflammatory drugs or acetaminophen: a post hoc pooled analysis of 2 randomized, placebo-controlled trials. Pain Res. Treat. 2012:296710.

Stone, T. W., and Perkins, M. N. (1981). Quinolinic acid: a potent endogenous excitant at amino acid receptors in CNS. Eur. J. Pharmacol. 72, 411-412. doi: 10.1016/0014-2999(81)90587-2

Sweitzer, S. M., Hickey, W. F., Rutkowski, M. D., Pahl, J. L., and DeLeo, J. A. (2002). Focal peripheral nerve injury induces leukocyte trafficking into the central nervous system: potential relationship to neuropathic pain. Pain 100, 163-170. doi: 10.1016/s0304-3959(02)00257-9

Tegeder, I., Adolph, J., Schmidt, H., Woolf, C. J., Geisslinger, G., and Lötsch, J. (2008). Reduced hyperalgesia in homozygous carriers of a GTP cyclohydrolase 1 haplotype. Eur. J. Pain 12, 1069-1077. doi: 10.1016/j.ejpain.2008.02.004

Tegeder, I., Costigan, M., Griffin, R. S., Abele, A., Belfer, I., Schmidt, H., et al. (2006). GTP cyclohydrolase and tetrahydrobiopterin regulate 
pain sensitivity and persistence. Nat. Med. 12, 1269-1277. doi: 10.1038/ nm1490

Thöny, B., Auerbach, G., and Blau, N. (2000). Tetrahydrobiopterin biosynthesis, regeneration and functions. Biochem. J. 347(Pt 1), 1-16. doi: 10.1042/bj3470001

Treede, R. D., Rief, W., Barke, A., Aziz, Q., Bennett, M. I., Benoliel, R., et al. (2019). Chronic pain as a symptom or a disease: the IASP classification of chronic pain for the international classification of diseases (ICD-11). Pain 160, 19-27.

Turski, W. A., Nakamura, M., Todd, W. P., Carpenter, B. K., Whetsell, W. O. Jr., and Schwarcz, R. (1988). Identification and quantification of kynurenic acid in human brain tissue. Brain Res. 454, 164-169. doi: 10.1016/0006-8993(88) 90815-3

Varrassi, G., Müller-Schwefe, G., Pergolizzi, J., Orónska, A., Morlion, B., Mavrocordatos, P., et al. (2010). Pharmacological treatment of chronic pain the need for Change. Curr. Med. Res. Opin. 26, 1231-1245.

Werner, E. R., Blau, N., and Thöny, B. (2011). Tetrahydrobiopterin: biochemistry and pathophysiology. Biochem. J. 438, 397-414. doi: 10.1042/bj20110293

Werner, E. R., Werner-Felmayer, G., Fuchs, D., Hausen, A., Reibnegger, G. Yim, J. J., et al. (1990). Tetrahydrobiopterin biosynthetic activities in human macrophages, fibroblasts, THP-1, and T 24 cells: GTP-cyclohydrolase I is stimulated by interferon- $\gamma$, and 6-pyruvoyl tetrahydropterin synthase and sepiapterin reductase are constitutively present. J. Biol. Chem. 265, 3189-3192.

Werner-Felmayer, G., Werner, E. R., Fuchs, D., Hausen, A., Reibnegger, G., and Wachter, H. (1989). Characteristics of interferon induced tryptophan metabolism in human cells in vitro. Biochimica et biophysica acta 14, 140-147. doi: 10.1016/0167-4889(89)90087-6

Wolf, H. (1974). The effect of hormones and vitamin B6 on urinary excretion of metabolites of the kynurenine pathway. Scand. J. Clin. Lab. Invest. Suppl. 136, $1-186$.

Woolf, C. J. (1983). Evidence for a central component of post-injury pain hypersensitivity. Nature 306, 686-688. doi: 10.1038/306686a0
Woolf, C. J. (2010). What is this thing called pain? J. Clin. Invest. 120, 3742-3744. Woolf, C. J. (2018). Pain amplification-A perspective on the how, why, when, and where of central sensitization. J. Appl. Biobehav. Res. 23:e12124. doi: 10.1111/ jabr. 12124

Woolf, C. J., and Costigan, M. (1999). Transcriptional and posttranslational plasticity and the generation of inflammatory pain. Proc. Natl. Acad. Sci. U.S.A. 96, 7723-7730. doi: 10.1073/pnas.96.14.7723

Woolf, C. J., and Ma, Q. (2007). Nociceptors-noxious stimulus detectors. Neuron 55, 353-364. doi: 10.1016/j.neuron.2007.07.016

Woolf, C. J., and Salter, M. W. (2000). Neuronal plasticity: increasing the gain in pain. Science 288, 1765-1768. doi: 10.1126/science.288.5472.1765

Zhu, X. H., Lu, M., Lee, B.-Y., Ugurbil, K., and Chen, W. (2015). In vivo NAD assay reveals the intracellular NAD contents and redox state in healthy human brain and their age dependences. Proc. Natl. Acad. Sci. U.S.A. 112, 2876-2881. doi: $10.1073 /$ pnas. 1417921112

Zhuang, Z. Y., Gerner, P., Woolf, C. J., and Ji, R.-R. (2005). ERK is sequentially activated in neurons, microglia, and astrocytes by spinal nerve ligation and contributes to mechanical allodynia in this neuropathic pain model. Pain 114, 149-159. doi: 10.1016/j.pain.2004.12.022

Conflict of Interest: The authors declare that the research was conducted in the absence of any commercial or financial relationships that could be construed as a potential conflict of interest.

Copyright (c) 2020 Staats Pires, Tan, Heng, Guillemin and Latini. This is an openaccess article distributed under the terms of the Creative Commons Attribution License (CC BY). The use, distribution or reproduction in other forums is permitted, provided the original author(s) and the copyright owner(s) are credited and that the original publication in this journal is cited, in accordance with accepted academic practice. No use, distribution or reproduction is permitted which does not comply with these terms. 